\title{
A Volumetric Metric for Monitoring Intracranial Aneurysms: Repeatability and Growth Criteria in a Longitudinal MR Imaging Study
}

\author{
(D)X. Liu, (D) H. Haraldsson, (D) Y. Wang, (D). Kao, (D) M. Ballweber, (D)A.J. Martin, (D)C.E. McCulloch, (D) Faraji, and (DD. Saloner,
} for the UCSF Intracranial Aneurysm Monitoring Group

\begin{abstract}
BACKGROUND AND PURPOSE: The reliability of contrast-enhanced MRA in monitoring serial volumetric changes of unruptured intracranial aneurysms has not been established. We aimed to determine the coefficient of variance of contrast-enhanced MRA in measuring aneurysm volumes, thus establishing criteria for aneurysm growth and permitting identification of variables predictive of growth.
\end{abstract}

MATERIALS AND METHODS: Aneurysm volumes were measured from serial contrast-enhanced MRA studies of patients with untreated intracranial aneurysms who underwent $>2$ sequential MR imaging evaluations. After coregistering all sequential studies in 3D space for each aneurysm and signal intensity normalization, aneurysm volume was determined across all time points. A linear mixed effects model was built to estimate the coefficient of variance of the measurement as well as to determine predictive variables. Growth was defined as relative growth exceeding 2 times the measurement coefficient of variance (sudden growth, as 4 times the coefficient of variance).

RESULTS: A total of 95 patients with 112 aneurysms were included (5.9 scans during 4.0 years on average, 616 scan measurements in total). The coefficient of variance was $5.5 \%$ of the aneurysm volume, and the relative growth rate was dependent on the location: anterior cerebral artery, $4.52 \%$ per year; vertebral artery, 2.46\% per year; middle cerebral artery, $2.74 \%$ per year; basilar artery, $2.36 \%$ per year; internal carotid artery, $1.14 \%$ per year. Thirty-six of $112(32 \%)$ aneurysms were characterized as growing, and $11 / 36$ of them had an episode of sudden growth.

CONCLUSIONS: Volume measurement of unruptured intracranial aneurysms by contrast-enhanced MRA seems a reliable metric for tracking the growth trajectory of aneurysms. Furthermore, the aneurysm growth rate differs among different locations.

ABBREVIATIONS: $\mathrm{ACA}=$ anterior cerebral artery; CE-MRA = contrast-enhanced MRA; CV = coefficient of variance; UIA = unruptured intracranial aneurysm

$\mathrm{t}$ is estimated that approximately $3 \%-5 \%$ of the population may have unruptured intracranial aneurysms (UIAs). ${ }^{1}$ The most acute complication of UIAs is rupture, which has a high rate of mortality and morbidity. ${ }^{2}$ However, only a small percentage of aneurysms ever rupture. ${ }^{3}$ Small UIAs are often followed with repeat imaging, with the intention to treat the aneurysm after it has demonstrated growth. ${ }^{4}$ Although multiple studies have explored the natural history of UIAs, current clinical evaluation relies heavily on traditional factors such as UIA diameter, diameter growth on serial imaging, hemorrhagic history, and clinical

Received December 9, 2020; accepted after revision April 1, 2021.

From the Department of Interventional Neuroradiology (X.L.), Beijing Tiantan Hospital, Capital Medical University, Beijing, China; Departments of Radiology and Biomedical Imaging, and Epidemiology and Biostatistics (X.L., H.H., Y.W., E.K., M.B., A.J.M., C.E.M., F.F., D.S.), University of California San Francisco, San Francisco, Californa; and Department of Radiology (Y.W.), Sichuan Provincial People's Hospital, University of Electronic Science and Technology of China, Chengdu, China.

Funding was provided by research award NS059944 (D.S.) from the National Institutes of Health.

X. Liu and H. Haraldsson contributed equally to this work. symptoms. ${ }^{5,6}$ UIA diameter growth is of particular clinical concern because previous studies have shown it to be a key risk factor for intracranial aneurysmal rupture. ${ }^{7-9}$ However, intracranial aneurysms can present with irregular and complicated geometries, and the accurate and reproducible measurement of aneurysmal diameter is challenging. ${ }^{10}$ Volume has been proposed as a more sensitive and comprehensive parameter for evaluation of aneurysm size compared with diameter measured on a $2 \mathrm{D}$ plane. ${ }^{11-13}$ While various methods have been developed for aneurysm volume calculation, ${ }^{14}$ they lack validation and little is currently known about the growth trajectory of UIAs when assessed by volumetric metrics.

The choice of imaging technique for monitoring UIAs requires careful consideration. Although providing excellent and robust

Please address correspondence to Yuting Wang, PhD, Department of Radiology and Biomedical Imaging, University of California San Francisco, San Francisco, 94121; e-mail: wangyuting_330@163.com

- Indicates open access to non-subscribers at www.ajnr.org

http://dx.doi.org/10.3174/ajnr.A7190 


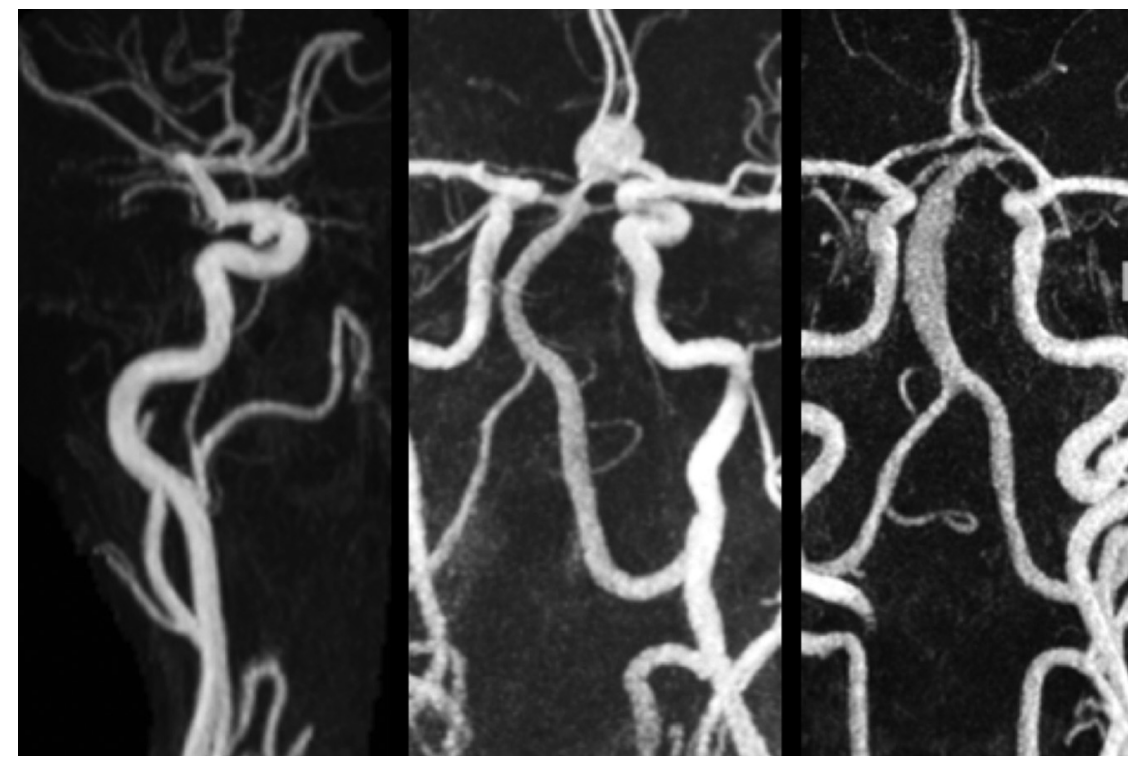

FIG 1. Maximum intensity projections of CE-MRA studies from 3 subjects. A, Subject with a saccular aneurysm of the internal carotid artery. $B$, Subject with a saccular aneurysm of the anterior communicating artery. C, Subject with a fusiform vertebral artery aneurysm. the lengthy enrollment period, informed consent was always obtained for use of the image data. Inclusion criteria were the following: 18-100 years of age; diagnosed with at least 1 UIA that was not scheduled for surgical or endovascular treatment; and having undergone $>2$ follow-up imaging sessions. Exclusion criteria were the following: metal implants, claustrophobia, or allergy to MR contrast agents. Subjects were asked to return every 6 months for CE-MRA. Patient demographic data and cardiovascular risk factors were recorded. Study end points included operative repair, aneurysm rupture, loss to followup, or death.

\section{MRA Surveillance Protocol}

In the first years of the study, imaging was performed on a $1.5 \mathrm{~T}$ scanner (Achieva; Philips, Healthcare) and in later years on a 3T scanner (Skyra; Siemens).

A weight-adjusted single dose of Gd-DTPA, diluted with saline to a results, conventional angiography and CT angiography are unsuited for serial monitoring due to invasiveness and the associated radiation dose, respectively. While contrast-enhanced MRA (CE-MRA) is minimally invasive and provides volumetric data, the reliability of CE-MRA has been verified using DSA. ${ }^{15}$ However, the repeatability of this technique has not been established for UIAs.

A reliable and well-characterized metric of change in aneurysm dimensions would help to differentiate important features of the underlying growth trajectory. For example, most previous studies have assumed a linear and continuous aneurysm growth pattern and used only the baseline and final time points to calculate the growth rate. ${ }^{3,7,16}$ This feature obscures cases in which aneurysms exhibit periods of intermittent rapid growth following a period of relative stability. Sudden aneurysmal growth could implicate a more acute pathologic process such as inflammation that requires more aggressive clinical management, whereas the conventional evaluation would underestimate recent rapid growth, diluting it by the overall growth rate calculation.

This study aimed to establish the coefficient of variance (CV) of volumetric measurement by CE-MRA to establish a criterion for likely aneurysm growth and, further, to identify variables predictive of growth.

\section{MATERIALS AND METHODS Patient Population}

This prospective study was conducted under institutional review board approval of the UCSF Medical Center. All subjects gave written informed consent for study participation. Patients with UIAs were recruited between April 2001 and July 2019 for serial MR imaging monitoring studies. Although initially recruited as part of a National Institutes of Health-funded study, this study was later implemented as part of the clinical routine, and despite
$22-\mathrm{mL}$ volume, was injected at $2 \mathrm{~mL} / \mathrm{s}$ through an intravenous catheter placed in the antecubital vein. The delay between contrast injection and arrival at the aneurysm,

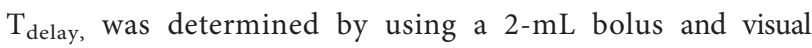
inspection of the resulting dynamic series of images collected at 1second intervals. A CE-MRA was then acquired using a 3D paracoronal slab with data acquisition initiated at a $\mathrm{T}_{\text {delay }}$ of 3 seconds following the start of a $20-\mathrm{mL}$ injection. Representative images are shown in Fig 1.

At $1.5 \mathrm{~T}$, imaging was performed with either a 6-channel head coil or a 16-channel head/neck coil. Imaging included contrastenhanced angiography (3D spoiled gradient-echo: $\mathrm{FOV}=$ $240 \times 180 \times 54 \mathrm{~mm}$, matrix $=400 \times 286 \times 45, \mathrm{TR} / \mathrm{TE}=5.0 /$ $1.8 \mathrm{~ms}$, flip angle $=30^{\circ}$, sensitivity encoding factor $=2$, bandwidth $=302 \mathrm{~Hz} /$ pixel, scanning time $=34$ seconds). Elliptic-centric $k$-space with time to center was 6 seconds. The resultant resolution was $0.6 \times 0.6 \times 1.2 \mathrm{~mm}$.

At $3 \mathrm{~T}$, imaging was performed with a 20-channel head/ neck coil. Imaging included contrast-enhanced angiography ( $3 \mathrm{D}$ spoiled gradient-echo: $\mathrm{FOV}=223 \times 181 \times 84 \mathrm{~mm}$, matrix $=320 \times 260 \times 120, \mathrm{TR} / \mathrm{TE}=3.7 / 1.4 \mathrm{~ms}$, flip angle $=20^{\circ}$, generalized autocalibrating partially parallel acquisition factor $=3$, bandwidth $=505 \mathrm{~Hz} /$ pixel, scanning time $=$ 30 seconds). Elliptic-centric $k$-space with time to center was 6 seconds. The resultant images had an isotropic resolution of $0.7 \times 0.7 \times 0.7 \mathrm{~mm}$.

\section{Longitudinal Analysis of the Aneurysm Volume}

Analysis of the aneurysm volume was performed with 2 thresholding iterations. The threshold for the baseline study was selected using the same windowing techniques as in clinical practice to maximize luminal volume while excluding extraluminal 

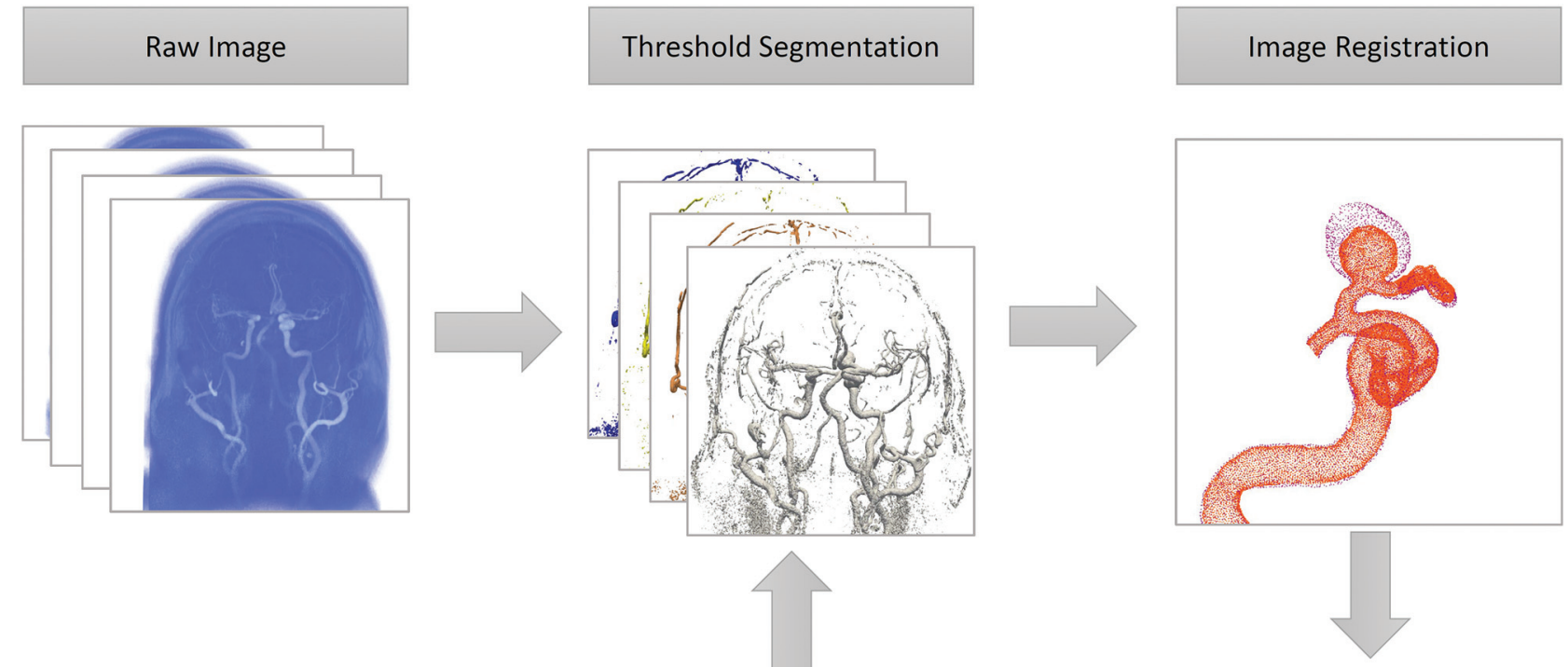
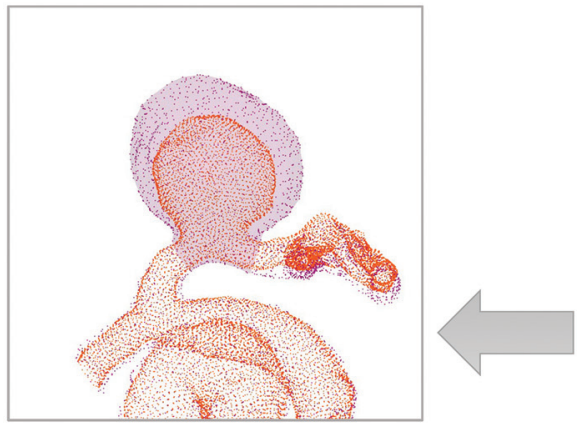

Record Results

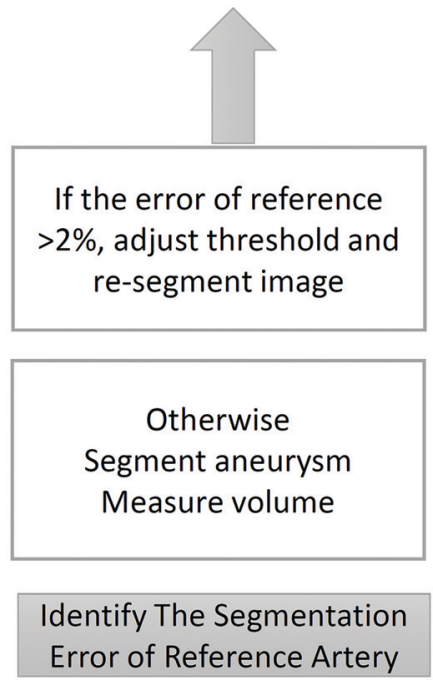

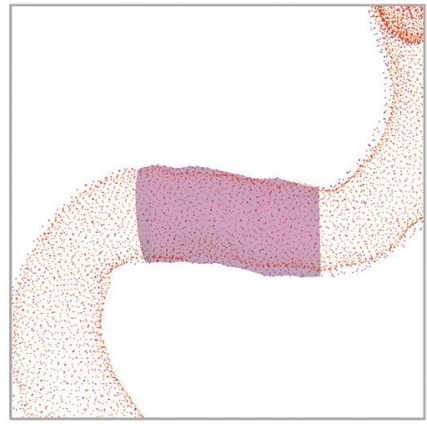

Segment Reference Artery

FIG 2. Diagram of the pipeline of aneurysm volume measurement.

regions. This selection was repeated on all consecutive datasets, and the $3 \mathrm{D}$ volumes were then placed into spatial coregistration.

The second thresholding step was performed using a reference length of vessel that was considered disease-free and presumed to have an unchanged volume during all time points. Interstudy calibration was enforced by adjusting the intensity threshold of each subsequent session to yield a measured volume of the reference artery that matched that of the baseline study to within $\pm 2 \%$. Identification of the reference vessel varied with the location of the aneurysm. In general, a branch-free, relatively straight segment of the parent vessel was selected a few centimeters proximal to the aneurysm. For the most common aneurysm type, the ICA, this was typically in the petrous portion of the ICA.

The processing pipeline is illustrated in Fig 2. DICOM images were exported in the Visualization ToolKit format. Isosurfaces for baseline and follow-up studies were imported into the 3D modeling software Geomagic Design X (3D Systems) and were coregistered to the baseline study using a picked point, landmark-based registration. The volume of the reference length was measured. If it differed from that in baseline, the threshold was adjusted and a new isosurface was generated. This process was repeated iteratively until volume matching was achieved for the reference length. Cut planes were then prescribed transverse to the arteries at the proximal and distal ends of the aneurysmal segment, and the volume contained within the isosurfaces between those planes was calculated.

\section{Statistical Methods}

The data were analyzed in $\mathrm{R}$ statistical and computing software (Version 3.61; http://www.r-project.org/) using linear mixed effects modeling (lmerTest ${ }^{17}$ for a linear mixed effect model; https://cran.r-project.org/web/packages/lmerTest/index.html). Homoscedasticity was obtained by log-transforming the aneurysm volumes, and time was centered for each patient. Time was included as a fixed effect, and the intercepts and slopes of the log-volume for patients and aneurysms were included as random effects. First, it was determined whether a quadratic time component was needed (Satterthwaite method, $P<.05)$. Second, whether the residual differed between $1.5 \mathrm{~T}$ and $3 \mathrm{~T}$ (Levene test, $P<.05$ ) was investigated. The CV was obtained from the variance of the residuals as

$\mathrm{CV}=(\mathrm{SD}$ of Original Scale $) /($ Mean of Original Scale $)=$ sqrt [exp(Variance of Log-Transformed Residuals) - 1].

Predictive variables were identified using a stepwise forward selection followed by a backward elimination (Satterthwaite method, $P<.05)$.

Noticeable growth was defined as relative growth $>2$ times the CV (compared with the initial volume). Sudden growth 
was defined as relative growth larger than 4 times the CV per year in consecutive follow-up measurements with no growth before and subsequent to that time interval.

\section{RESULTS}

A total of 101 patients who underwent $>2 \mathrm{MR}$ imaging scans were included in this longitudinal study. For any subject in whom there was an apparent decrease in aneurysm volume, true FISP images were examined to see whether there was any wall thickening encroaching on the lumen, indicating thrombus layering in the aneurysm rather than simply measurement error that accounted for this volume change. Six aneurysms were noted to layer intraluminal thrombus during follow-up and were excluded from analysis. Hence the statistical analysis was performed on the basis of 95 patients with 112 aneurysms, and a total of 616 measurements (Figs 3-4).

The average maximal diameter of 112 aneurysms was $6.1 \mathrm{~mm}$. The mean follow-up time for this cohort was 4.0 years, and the mean number of imaging sessions was 5.9. Detailed patient and aneurysm characteristics are presented in Table 1.

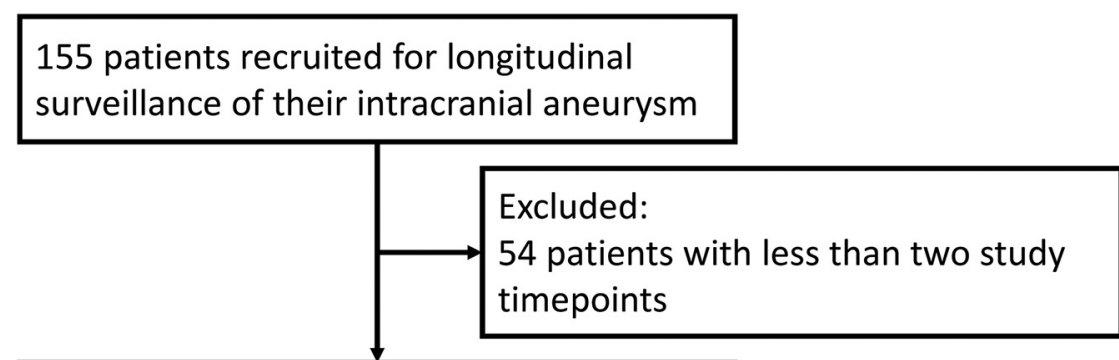

101 patients with more than two timepoints
Excluded:

6 patients whose aneurysms showed thrombus layering at any study timepoint

\section{5 patients with more than two timepoints}

and aneurysms without any thrombus layering

\section{Coefficient of Variance and Identification of Predictive Variables of Growth from Linear Mixed Effect Modeling}

Including a quadratic time term did not improve the model significantly $(P=.32)$. No significant difference of the residuals was found between acquisitions at $1.5 \mathrm{~T}$ and $3 \mathrm{~T}(P=.26)$. The CV was determined to be $5.5 \%$.

Among the investigated terms (aneurysm location, saccular versus nonsaccular aneurysms, sex, hypertension, hyperlipidemia, smoking, diabetes, age, and the presence of multiple aneurysms) as potential fixed effects in the best-fit linear mixed effect model, aneurysm volume growth varied by age and location, with the fastest growth in anterior cerebral artery (ACA) aneurysms, as summarized in Table 2.

FIG 3. Patient selection flow chart.
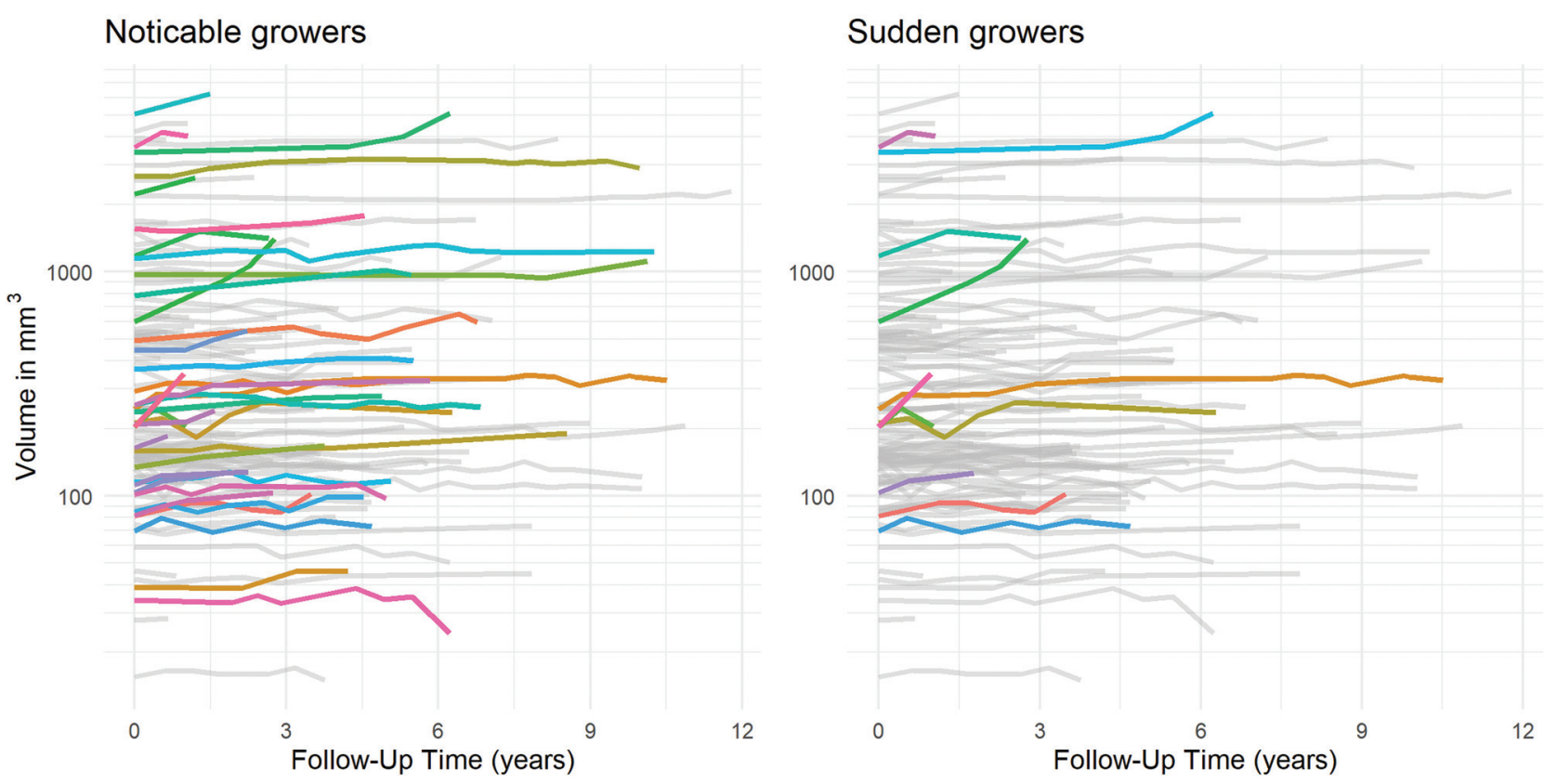

FIG 4. Plots showing evolution across time of volume for each of the 112 aneurysms. Color coding is used to highlight noticeable growers (left) and sudden growers (right). 
Table 1: Demographics ${ }^{a}$

\begin{tabular}{lc}
\hline \multicolumn{1}{c}{ Variable } & Value \\
\hline No. of patients & 95 \\
No. of aneurysms & 112 \\
Age (mean) (yr) & $61.1(\mathrm{SD}, 17.4)$ \\
Female & $62(65.3 \%)$ \\
Male & $33(34.7 \%)$ \\
Hypertension & $42(44.2 \%)$ \\
Hyperlipidemia & $20(21.1 \%)$ \\
Smoking & $32(33.7 \%)$ \\
Diabetes & $11(11.6 \%)$ \\
Fusiform & $27(28.4 \%)$ \\
Nonfusiform & $68(71.6 \%)$ \\
ICA [mean diameter \pm SD (mm)] & $67(59.8 \%)[6.09 \pm 4.57]$ \\
ACA [mean diameter $\pm S D(m m)]$ & $10(8.9 \%)[4.36 \pm 2.37]$ \\
MCA [mean diameter $\pm S D(m m)]$ & $11(9.8 \%)[4.74 \pm 2.36]$ \\
Vertebral artery [mean diameter $\pm S D$ & $6(5.4 \%)[5.95 \pm 2.83]$ \\
$\quad$ (mm)] & $18(16.1 \%)[8.09 \pm 4.01]$ \\
Basilar artery [mean diameter $\pm S D$ & \\
(mm)] & $4.0(S D, 2.8)$ \\
Follow-up time (mean) (yr) & $5.9(S D, 3.4)$ \\
No. of imaging sessions per patient & \\
(mean) & $6.1(S D, 4.2)$ \\
Maximal diameter (mean) (mm) & $246.7(139.1-663.8)$ \\
Baseline volume (mean) (mm $\left.{ }^{3}\right)$ &
\end{tabular}

Note:-SD indicates standard deviation.

${ }^{a}$ Data are No. (\%) unless otherwise indicated.

Table 2: Growth and $95 \% \mathrm{Cl}$ of the relative growth

\begin{tabular}{lcc}
\hline & \multicolumn{2}{c}{ Relative Aneurysm Growth per Year (\%) } \\
\cline { 2 - 3 } & Estimates & \multicolumn{1}{c}{$95 \% \mathrm{Cl}$} \\
\hline ACA & 4.07 & $2.28-5.87$ \\
VA & 1.66 & $-0.44-4.03$ \\
MCA & 1.41 & $-0.10-3.22$ \\
BA & 1.32 & $-0.21-2.78$ \\
ICA & 0.47 & $-0.25-1.19$ \\
Change per age (yr) & -0.044 & $-0.086-0.000$ \\
\hline
\end{tabular}

Note:-BA indicates basilar artery; VA, vertebral artery.

\section{Clinical Interpretation Using the Proposed Methodology}

By means of the volumetric metric suggested in this study to monitor intracranial aneurysms, noticeable growth would be defined as relative growth of $>2$ times the CV (11\%) compared with the initial volume. Requiring change to be $>2$ times the $\mathrm{CV}$ implies that there is $95 \%$ statistical confidence that there has been a true change in aneurysm size and that the perceived change is not just measurement variability. In our study population, $8 \%$ of aneurysms had an average growth rate that would have resulted in noticeable growth in 1 year of follow-up.

Sudden growth was defined as 4 times the CV (22\%) volume growth in consecutive follow-up intervals. If this methodology were applied to the patients included in this study, it would conclude that 36 of the 112 aneurysms (32\%) demonstrated noticeable growth during the course of the study and that 11 of the $36(31 \%)$ aneurysms with noticeable growth had an episode of sudden growth.

\section{DISCUSSION}

This study investigated the use of a volumetric measure to monitor UIAs across time in imaging studies with a large number of follow- up time points. There are 3 key findings: First, the analysis demonstrates that CE-MRA, a relatively noninvasive imaging method, provides volume measurements with a $\mathrm{CV}$ of $5.5 \%$. This corresponds, in most intracranial aneurysms, to an error of measurement of less than a voxel in terms of linear measurements, the conventional clinical metric. Most important, this estimate incorporates all potential contributing sources of variance, including: physiologic factors such as cardiac output, which might vary between imaging sessions; acquisition errors related to imperfect timing of contrast injection; and postprocessing errors related to user-dependent choices such as thresholding and cut plane selections. Second, the study showed that the growth rate was dependent on age and the location of the aneurysm, with UIAs of the ACA showing the fastest growth rate of $4.52 \%$ per year. Third, $11 / 112(9.8 \%)$ of the UIAs presented with what appeared to be an episode of sudden growth.

Measurements of aneurysms in terms of volume is attractive because of its potential to provide a more sensitive and comprehensive assessment of change. ${ }^{18}$ Several software-based methods of volume measurement have been implemented on CTA images. ${ }^{14}$ CE-MRA has advantages in the serial monitoring of untreated UIAs because there is no radiation (as in CTA) or arterial catheterizationrelated risks (as in conventional angiography). CE-MRA also is not subject to flow-related artifacts, specifically saturation effects that are pronounced in slowly rotating intra-aneurysmal blood, and the benefits provided by the increased reliability of this approach are considered, in a high-risk disease condition, to outweigh the known risks of gadolinium administration. However, reliable CE-MRA measurements in longitudinal studies are challenging. They require coregistration in $3 \mathrm{D}$ space and also lack an absolute signal calibration for standardized thresholding-unlike CTA, which is measured in Hounsfield units. ${ }^{19,20}$ In this study, surface meshes of thresholded vascular territories from all time points were brought into coregistration using internal fiducials and an affine transformation. Thresholding consistency was enforced by constraining the volume of a reference length of the vessel to remain constant during all time points. Using this in-house software, we found an acceptable CV (5.5\%) in the measurement of UIAs.

The existing literature on assessing aneurysm size is principally based on 2D diameter measurements. Reports on the rate of growth and risk factors for growth of UIAs are inconsistent. ${ }^{8,21-24}$ Furthermore, most previous studies used only 2 time points (the first and the last) to evaluate aneurysm growth, thus excluding important information on the growth trajectory in the intervening periods. ${ }^{3,7,16,25}$ Using such datasets, most studies assume that aneurysm growth is linear and steady, though clinical observation or even proposed growth models ${ }^{3,16}$ cause skepticism about this assumption. In this study, we included the often-neglected intermediate events and more sensitively identified a higher percentage of growing aneurysms (32\%) than in previous studies (4\% 18\%). ${ }^{3,4,7,8,21,26-29}$ Further analysis of growth trends revealed that approximately $31 \%$ of growing aneurysms presented with a sudden/episodic growth pattern, the presentation of which is of high clinical concern. A better understanding of the growth trajectory and pattern of aneurysms will support a more judicious selection of UIAs for preventative treatment and enable the development of improved follow-up strategies for UIAs. ${ }^{3}$ 
Two recent meta-analyses reported aneurysm size, female sex, smoking, cavernous carotid artery location, and nonsaccular shape as independent risk factors for UIA growth. The roles of other risk factors were inconsistent. ${ }^{29-31}$ Despite a partial overlap, several of these findings were not replicated in this study. Possible reasons for the discordance were the following: 1) The reported aneurysm sizes were all in terms of $2 \mathrm{D}$ diameters, while volumetric measures might display a different dependence; and 2) this cohort for aneurysm monitoring had generally small-sized UIAs, and the results presented here might better reflect the growth behavior of relatively small UIAs.

This study has several limitations. First, there was possible patient selection bias because the preference of patients for participating in a monitoring study could result in an over-representation of patients with relatively smaller UIAs. Also, patients with known risk factors such as a history of subarachnoid hemorrhage were not included because near-term treatment was likely. Second, it is difficult to validate the accuracy of the volume measurement method in serial studies in clinical patients against the current criterion standard of DSA, given the invasive nature of the latter. Third, because the diagnostic criteria for aneurysm sudden growth have not been explored previously, the criteria used here were based on our clinical experience. Finally, in this study, we enrolled all suitable subjects referred to us by referring clinicians. It is apparent that the clinicians were more comfortable referring aneurysms of the ICA for surveillance imaging than aneurysms in other locations where interventional treatment could have been preferred. As a result, the total number of ACA, $\mathrm{MCA}$, and vertebral artery aneurysms was relatively small, and the result that the ACA location was significantly associated with greater volume growth should be interpreted with caution.

\section{CONCLUSIONS}

This proposed method of aneurysm volume measurement provides an acceptable CV for longitudinal follow-up studies compared with prior linear metrics. Approximately one-fourth of UIAs showed noticeable growth with time, and approximately one-third of these growing UIAs presented with a sudden/episodic growth pattern. Aneurysm volume measurement appears to be a sensitive and useful tool to depict and identify the growth trajectory and patterns of UIAs.

\section{The UCSF Intracranial Aneurysm Monitoring Group}

M.R. Amans, MD, D.L. Cooke, MD, C.F. Dowd, MD, V. Halbach, MD, S.W. Hetts, MD, R.T. Higashida, MD, C. Huang, MD, D. Hurwit, MD, N. Jeung, RT, S.A. Josephson, MD, A. Kim, MD, N.U. Ko, MD, M.T. Lawton, MD, W.A. Lee, MD, D. Nieuwoudt, MD, V. Rayz, PhD, S. Sohrabi, MD, W.S. Smith, $\mathrm{MD}, \mathrm{PhD}$, and C. Zhu, PhD.

Disclosures: Charles E. McCulloch-RELATED: Grant: National Institutes of Health. Alastair J. Martin—RELATED: Grant: National Institutes of Health.* *Money paid to the institution.

\section{REFERENCES}

1. Brisman JL, Song JK, Newell DW. Cerebral aneurysms. $N$ Engl J Med 2006;355:928-39 CrossRef Medline
2. Rincon F, Rossenwasser RH, Dumont A. The epidemiology of admissions of nontraumatic subarachnoid hemorrhage in the United States. Neurosurgery 2013;73:217-22 CrossRef Medline

3. Chien A, Callender RA, Yokota $H$, et al. Unruptured intracranial aneurysm growth trajectory: occurrence and rate of enlargement in 520 longitudinally followed cases. J Neurosurg 2019;132:1077-87 CrossRef Medline

4. Bor AS, Tiel Groenestege AT, terBrugge KG, et al. Clinical, radiological, and flow-related risk factors for growth of untreated, unruptured intracranial aneurysms. Stroke 2015;46:42-48 CrossRef Medline

5. Etminan N, Beseoglu K, Barrow DL, et al. Multidisciplinary consensus on assessment of unruptured intracranial aneurysms: proposal of an international research group. Stroke 2014;45:1523-30 CrossRef Medline

6. Greving JP, Wermer MJ, Brown RD Jr, et al. Development of the PHASES score for prediction of risk of rupture of intracranial aneurysms: a pooled analysis of six prospective cohort studies. Lancet Neurol 2014;13:59-66 CrossRef Medline

7. Villablanca JP, Duckwiler GR, Jahan R, et al. Natural history of asymptomatic unruptured cerebral aneurysms evaluated at CT angiography: growth and rupture incidence and correlation with epidemiologic risk factors. Radiology 2013;269:258-65 CrossRef Medline

8. Serrone JC, Tackla RD, Gozal YM, et al. Aneurysm growth and de novo aneurysms during aneurysm surveillance. I Neurosurg 2016;125:1374-82 CrossRef Medline

9. Watanabe Z, Tomura N, Akasu I, et al. Comparison of rates of growth between unruptured and ruptured aneurysms using magnetic resonance angiography. J Stroke Cerebrovasc Dis 2017;26:284954 CrossRef Medline

10. Ryu CW, Kwon OK, Koh JS, et al. Analysis of aneurysm rupture in relation to the geometric indices: Aspect ratio, volume, and volume-to-neck ratio. Neuroradiology 2011;53:883-89 CrossRef Medline

11. Wever JJ, Blankensteijn JD, Mali WP, et al. Maximal aneurysm diameter follow-up is inadequate after endovascular abdominal aortic aneurysm repair. Eur J Vasc Endovas Surg 2000;20:177-82 CrossRef Medline

12. Fillinger M; Excluder Bifurcated Endoprosthesis Clinical Investigators. Three-dimensional analysis of enlarging aneurysms after endovascular abdominal aortic aneurysm repair in the gore excluder pivotal clinical trial. J Vasc Surg 2006;43:888-95 CrossRef Medline

13. Lindquist Liljeqvist M, Hultgren R, Gasser TC, et al. Volume growth of abdominal aortic aneurysms correlates with baseline volume and increasing finite element analysis-derived rupture risk. $J$ Vasc Surg 2016;63:1434-42 CrossRef Medline

14. Escobar-de la Garma VH, Zenteno M, Padilla-Vazquez F, et al. Comparative analysis of aneurysm volume by different methods based on angiography and computed tomography angiography. Neurosurg Rev 2018;41:1013-19 CrossRef Medline

15. Persson A, Dahlström N, Engellau L, et al. Volume rendering compared with maximum intensity projection for magnetic resonance angiography measurements of the abdominal aorta. Acta Radiol 2004;45:453-59 CrossRef Medline

16. Brady AR, Thompson SG, Fowkes FG, et al. Abdominal aortic aneurysm expansion: risk factors and time intervals for surveillance. Circulation 2004;110:16-21 CrossRef Medline

17. Kuznetsova A, Brockhoff PB, Christensen RH. Lmertest package: tests in linear mixed effects models. J Stat Softw 2017;82:1-26 CrossRef

18. Erhardt S, Marbacher S, Neuschmelting V, et al. Comparison between routine cylindrical cerebral aneurysm volume approximation and three-dimensional volume measurements in experimental aneurysms. Neurol Res 2014;36:739-45 CrossRef Medline

19. Piotin M, Gailloud P, Bidaut L, et al. CT angiography, MR angiography and rotational digital subtraction angiography for volumetric 
assessment of intracranial aneurysms: an experimental study. Neuroradiology 2003;45:404-09 CrossRef Medline

20. Hanley M, Zenzen WJ, Brown MD, et al. Comparing the accuracy of digital subtraction angiography, CT angiography and MR angiography at estimating the volume of cerebral aneurysms. Interv Neuroradiol 2008;14:173-77 CrossRef Medline

21. Burns JD, Huston J 3rd, Layton KF, et al. Intracranial aneurysm enlargement on serial magnetic resonance angiography: frequency and risk factors. Stroke 2009;40:406-11 CrossRef Medline

22. Chien A, Liang F, Sayre J, et al. Enlargement of small, asymptomatic, unruptured intracranial aneurysms in patients with no history of subarachnoid hemorrhage: the different factors related to the growth of single and multiple aneurysms. J Neurosurg 2013;119:19097 CrossRef Medline

23. Koffijberg H, Buskens E, Algra A, et al. Growth rates of intracranial aneurysms: exploring constancy. J Neurosurg 2008;109:176-85 CrossRef Medline

24. Sonobe M, Yamazaki T, Yonekura M, et al. Small unruptured intracranial aneurysm verification study: Suave Study, Japan. Stroke 2010;41:1969-77 CrossRef Medline

25. Leemans EL, Cornelissen BM, Said M, et al. Intracranial aneurysm growth: consistency of morphological changes. Neurosurg Focus 2019;47:E5 CrossRef Medline
26. Huang $\mathrm{H}$, O’Neill AH, Chandra RV, et al. Asymptomatic intracranial aneurysms in the elderly: long-term clinical and radiological follow up of 193 consecutive patients. World Neurosurg 2020;133: e600-08 CrossRef Medline

27. Matsumoto K, Oshino S, Sasaki M, et al. Incidence of growth and rupture of unruptured intracranial aneurysms followed by serial MRA. Acta Neurochir 2013;155:211-16 CrossRef Medline

28. Gondar R, Gautschi OP, Cuony J, et al. Unruptured intracranial aneurysm follow-up and treatment after morphological change is safe: observational study and systematic review. J Neurol Neurosurg Psychiatry 2016;87:1277-82 CrossRef Medline

29. Jin D, Song C, Leng X, et al. A systematic review and meta-analysis of risk factors for unruptured intracranial aneurysm growth. Int $J$ Surg 2019;69:68-76 CrossRef Medline

30. Brinjikji W, Zhu YQ, Lanzino G, et al. Risk factors for growth of intracranial aneurysms: a systematic review and meta-analysis. AJNR Am J Neuroradiol 2016;37:615-20 CrossRef Medline

31. Backes D, Rinkel GJ, Laban KG, et al. Patient- and aneurysm-specific risk factors for intracranial aneurysm growth: a systematic review and meta-analysis. Stroke 2016;47:951-57 CrossRef Medline 